\title{
Loss of the tissue-specific proapoptotic BH3-only protein Nbk/Bik is a unifying feature of renal cell carcinoma
}

\author{
I Sturm ${ }^{1}$, C Stephan ${ }^{2}$, B Gillissen 1 , R Siebert ${ }^{3}$, M Janz ${ }^{1}$, \\ S Radetzki ${ }^{1}, \mathrm{~K}_{\text {Jung }}{ }^{2}, \mathrm{~S}$ Loening $^{2}$, B Dörken ${ }^{1}$ and PT Daniel ${ }^{*, 1}$ \\ 1 Department of Hematology, Oncology and Tumor Immunology, University \\ Medical Center Charité, Campus Berlin-Buch, Berlin, Germany \\ 2 Department of Urology, University Medical Center Charité, Campus \\ Berlin-Mitte, Berlin, Germany \\ ${ }^{3}$ Institute of Human Genetics, University Hospital Schleswig-Holstein, Campus \\ Kiel, Germany \\ * Corresponding author: PT Daniel, Clinical and Molecular Oncology, Charité - \\ Campus Berlin-Buch, Humboldt-University, Lindenberger Weg 80, Berlin-Buch \\ 13125, Germany. Tel.: + 49-30-9417-1642 or -1644; \\ Fax: + 49-30-9417-1644 or -1641; E-mail: pdaniel@mdc-berlin.de
}

Received 08.6.05; revised 01.8.05; accepted 11.8.05; published online 2.12.05 Edited by A Villunger

\begin{abstract}
We report for the first time inactivation of a tissue-specific Bcl-2 homology domain 3 (BH3)-only protein as a common aspect in human cancer. In detail, we show that loss of the BH3-only protein natural born killer ( $\mathrm{Nbk}$ )/Bcl-2-interacting killer (Bik) is a common feature of clear-cell renal cell carcinoma (RCC). While strong Nbk expression is found in the renal tubuli and the epithelial lining of the glomerula, a consistent loss of Nbk expression was observed in primary RCC tissue and RCC cell lines. Mutation of Nbk is, however, rare, whereas deletion of the Nbk gene at 22q13.2 is frequent. In addition to loss of heterozygosity (LOH), DNA methylation mediates transcriptional silencing of the Nbk gene. The conditional restoration of Nbk/Bik expression led to apoptotic death of RCC but not of nonmalignant renal epithelia. A broader expression analysis of RCC cell lines for BH3-only proteins revealed that loss of Nbk coincides with failure to express Bim, whereas Puma, Bid and BNIP3 are readily detectable and, in case of Puma, inducible by $\mathrm{p} 53$. These data delineate a role for defects in BH3-only proteins as tumor suppressors in RCC and may explain at the same time the impressive clinical apoptosis resistance of RCC.

Cell Death and Differentiation (2006) 13, 619-627.

doi:10.1038/sj.cdd.4401782; published online 2 December 2005
\end{abstract}

Keywords: Nbk/Bik; Bim; Puma; p53; BH3-only protein; Bcl-2 family; renal cell carcinoma

Abbreviations: Nbk, natural born killer; Bik, Bcl-2-interacting killer; Hrk, harakiri; RCC, renal cell carcinoma; $\mathrm{BH} 3, \mathrm{Bcl}-2$ homology domain 3; FISH, fluorescence in situ hybridization; $\mathrm{LOH}$, loss of heterozygosity; PCR, polymerase chain reaction; SSCP, single-strand conformational polymorphism; SNP, singlenucleotide polymorphism; 5'aza-2'dC, 5'-aza-2'-deoxycytidine

\section{Introduction}

The Bcl-2 family of proteins and its opposing groups of antiand proapoptotic members arbitrate life-or-death decisions. The apoptosis-promoting members of the $\mathrm{Bcl}-2$ family can be subdivided into the multi-Bcl-2-homology $(\mathrm{BH})$ domain members Bax, Bak, Bok and the growing subfamily of proteins sharing only the $\mathrm{BH} 3$ domain. ${ }^{1}$ The emerging function of these 'BH3-only' proteins appears to provide a link between various cell death sensors and the execution machinery of apoptosis. ${ }^{2}$ Thus, BH3-only proteins may function as death sensors that mediate activation of the mitochondrial apoptosis pathway in response to, for example, oncogenic stress signals or DNA damage. For example, Noxa and Puma are transcriptionally induced by $\mathrm{p} 53$ and mediate apoptosis induced by $\mathrm{p} 53 .{ }^{3}$ These proapoptotic activities of certain $\mathrm{BH} 3$-only proteins essentially depend on the presence of Bax and Bak. Additional findings indicate that some $\mathrm{BH} 3$-only proteins can promote apoptosis by two mutually nonexclusive mechanisms: by directly inactivating prosurvival $\mathrm{Bcl}-2$ proteins or through direct or indirect modification of Bax-like molecules. ${ }^{4-6}$ For some $\mathrm{BH} 3$-only proteins, including natural born killer (Nbk) and Puma, an entirely Bax-dependent mode of action was recently established, ${ }^{7-9}$ whereas others may act through the activation of Bak. ${ }^{7}$ Loss of Bax is a frequent event in human cancer and may be associated with poor prognosis and clinical resistance to anticancer therapy. ${ }^{10,11}$ Moreover, loss of the Bax gene was shown to contribute to oncogenic transformation $^{12}$ and tumor development in Bax-/- mice. ${ }^{13}$ Thus, not only deregulated expression of antiapoptotic Bcl-2 but also disruption of proapoptotic $\mathrm{Bcl}-2$ homologs is critically involved in tumorigenesis. In contrast, far less information is available regarding the consequences of $\mathrm{BH} 3$-only gene defects.

Various knockout mouse models have recently implicated loss of several BH3-only proteins in tumorigenesis. Published data show that targeted knockout of Bad facilitates development of high-grade lymphoma and that disruption of Bim accelerates lymphomagenesis in the $\mathrm{E} \mu$-myc model.${ }^{14}$ There, loss of Bim alleviates the need for inactivation of the p53/ p14 ${ }^{\mathrm{ARF}}$ pathway during lymphomagenesis. ${ }^{15}$ Disruption of $\mathrm{Bid}$ results in late-onset chronic myelomonocytic leukemia. ${ }^{16}$ This delineates the importance of BH3-only proteins in tumor surveillance. Nevertheless, a link between human disease and $\mathrm{BH} 3$-only protein deficiency could not be established so far. Here, we show for the first time that disruption of a specific $\mathrm{BH} 3-$ only protein is a common feature in a human cancer. Renal cell carcinoma (RCC) exhibit loss of Nbk and reexpression of Nbk triggers apoptotic death in RCC cells. Given the tissue-specific expression of Nbk with highest expression in renal cell epithelia, Nbk might therefore act as a renal tissue-specific tumor suppressor gene. This is supported by the observation that Nbk is a target of $p 53^{17}$ and has 
been implicated in the response to DNA damage-induced cell death. ${ }^{18}$ Loss of Nbk might therefore explain the impressive intrinsic resistance of RCC towards apoptosis induction.

\section{Results}

Normal kidney epithelia exhibit high expression of Nbk protein in the renal tubuli and the epithelial lining of the glomerula (Figure 1a). In contrast, surrounding connective tissues, mesangial cells of the glomerula and blood vessels do not express Nbk. Nbk expression is tissue specific and high

a
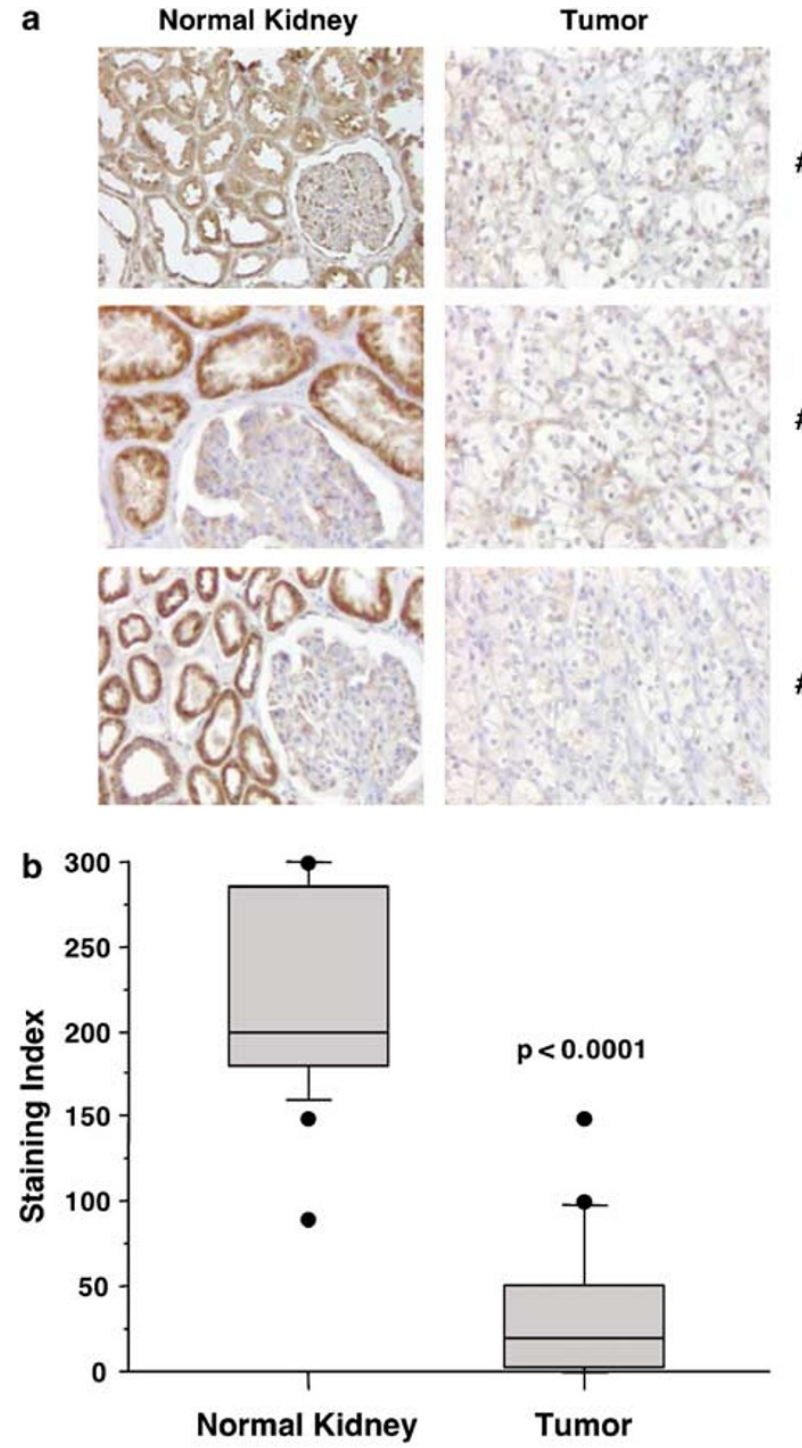

Figure $1 \mathrm{Nbk} / \mathrm{Bik}$ protein expression in nonmalignant renal tissue and in clearcell RCC. (a) Left column: normal kidney; right column: RCC cells show loss of Nbk/Bik expression. Magnification: $\times 200$. Paired samples from the same patient are shown. Renal tubules and glomerula lining epithelia show strong Nbk/ Bik expression. (b) Box-plot analysis for Nbk/Bik-protein expression in 28 paired samples (tumor and normal tissue from the same patient). Staining index (range $0-300$ ) was calculated as the product of percentage positive cells and staining intensities (0-3). Statistical significance was calculated by Wilcoxon's signedrank test expression is found only in the kidney ${ }^{19}$ and the involuting breast. $^{20}$ To investigate whether Nbk is a potential tumor suppressor, we studied Nbk expression, deletion and mutation in primary RCC carcinoma samples as compared with nonmalignant renal epithelia. In contrast to nonmalignant tissue that showed high expression of Nbk protein, a consistently weak expression or complete loss of Nbk was seen in all 57 clear-cell RCC studied (Figure 1). Similar data were obtained by the use of both antibodies against the $\mathrm{N}$ - or the C-terminus of Nbk. A direct comparison of normal renal tissue with cancer tissue on the same tissue slide was feasible in 28 patients. There, decrease of Nbk expression in RCC proved to be highly significant (Wilcoxon's signed-rank test, $P<0.0001$, Figure 1b). Clinicopathological data are listed in Table 1. Loss of Nbk/Bik protein expression was a general feature of the RCC tumors and did not correlate with the presence or absence of distant metastases, tumor grading, tumor size or involvement of lymph nodes $\left(\chi^{2}\right.$ test, $\left.P>0.1\right)$.

To clarify the mechanism of Nbk loss, we analyzed Nbk protein and RNA expression in RCC lines. In accordance with the immunohistochemistry data, Western blot analyses for Nbk expression in RCC cell lines showed low or absent protein expression. In nine of the $10 \mathrm{RCC}$ cell lines analyzed,

Table 1 Clinicopathological data $(n=57 \text { patients })^{\star}$

\begin{tabular}{|c|c|c|c|}
\hline & $n$ & $\begin{array}{c}n \\
\text { Codon } \\
26 \text { SNP }\end{array}$ & $\begin{array}{c}n \\
\text { Homozygous } \\
\text { intron } 3 \mathrm{CT} \\
\text { deletion }\end{array}$ \\
\hline \multicolumn{4}{|l|}{ Gender } \\
\hline Male & 39 & 2 & 17 \\
\hline Female & 18 & 1 & 6 \\
\hline $\begin{array}{l}\text { Age (median, } \\
\text { range) }\end{array}$ & $59.3(25-80)$ & 一 & - \\
\hline \multicolumn{4}{|l|}{ Clinical stage } \\
\hline UICC I & 0 & 0 & 0 \\
\hline UICC II & 20 & 2 & 9 \\
\hline UICC III & 8 & 0 & 3 \\
\hline UICC IV & 29 & 1 & 11 \\
\hline \multicolumn{4}{|l|}{$p T$} \\
\hline pT1 & 2 & 0 & 1 \\
\hline pT2 & $2 \overline{4}$ & 2 & 9 \\
\hline pT3 & 31 & 1 & 13 \\
\hline pT4 & 0 & 0 & 0 \\
\hline \multicolumn{4}{|l|}{$p N$} \\
\hline pNO & 43 & 3 & 19 \\
\hline pN1 & 3 & 0 & 1 \\
\hline pN2 & 4 & 0 & 2 \\
\hline pN3 & 1 & 0 & 1 \\
\hline NA & 6 & 0 & 0 \\
\hline \multicolumn{4}{|l|}{$M$} \\
\hline MO & 29 & 2 & 12 \\
\hline M1 & 28 & 1 & 11 \\
\hline \multicolumn{4}{|l|}{$G$} \\
\hline G1 & 9 & 1 & 3 \\
\hline G2 & 35 & 2 & 15 \\
\hline G3 & 13 & 0 & 5 \\
\hline G4 & 0 & 0 & 0 \\
\hline
\end{tabular}

$\mathrm{NA}=$ not applicable ${ }^{\star}$ For all $P>0.2\left(\chi^{2}\right.$ test $)$ 
Protein

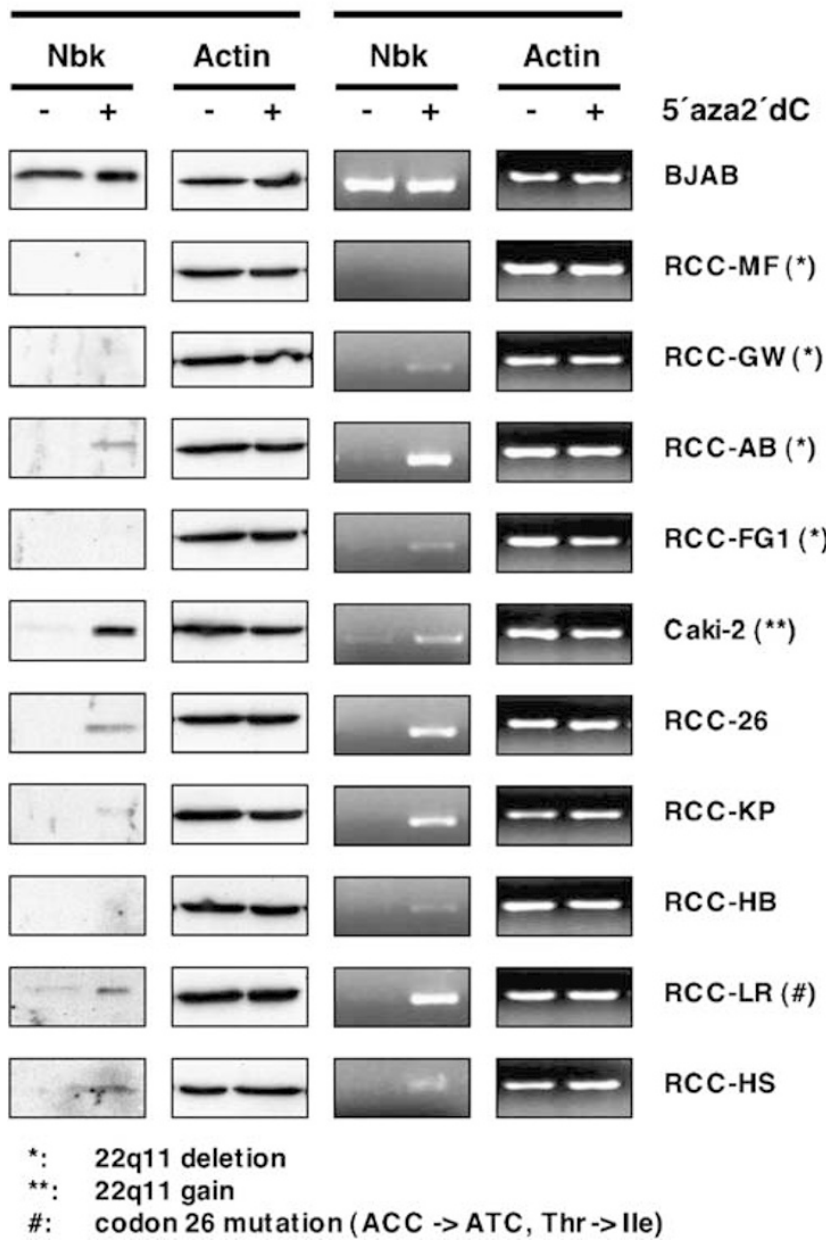

Figure 2 Cytogenetic status and impact of $5^{\prime} a z a-2^{\prime} \mathrm{dC}$ on Nbk protein and mRNA expression in RCC lines. Nbk protein expression was detected in 10 RCC cell lines by Western blot analysis (left panels) and Nbk mRNA was detected by semiquantitative RT-PCR (right panels) in the absence or presence of the DNA methylation inhibitor $5^{\prime}$-aza-2'-deoxycytidine ( $5^{\prime}$ aza-2' $\left.\mathrm{dC}\right)$. Chromosomal loss of the NBK/BIK gene at 22q13.2 was investigated by interphase FISH. Four cell lines showed signal patterns indicating loss of the NBK locus as compared to the ploidy level $\left({ }^{*}\right)$, whereas Caki-2 showed a signal pattern suggesting a gain of the NBK gene locus (**). RCC-LR carries the codon 26 SNP (ACC $\rightarrow$ ATC, Thr $\rightarrow$ Ile). $\beta$-actin served as a control for Western blot and RT-PCR analyses. BJAB cells served as a positive control for Nbk protein and mRNA detection. A homozygous intronic CT deletion in the intimate vicinity of the $3^{\prime}$ splice site of the intron 3/exon 4 boundary was found in RCC-GW, RCC-AB, RCC-FG-1, RCC-KP RCC-LR and RCC-HS. RCC MF is wild type (according to the published sequence), whereas in Caki-2 and RCC HB, the patterns are heterozygous

no constitutive Nbk mRNA was detected by RT-polymerase chain reaction (PCR) (Figure 2), indicating that loss of Nbk expression occurs either as a consequence of gene deletion or transcriptional silencing. Gene silencing that arises from methylation is an important epigenetic mechanism of tumor suppressor gene inactivation. Loss of gene expression by transcriptional silencing has been suggested for several cell death regulators, for example, for APAF-1 in melanoma and for procaspase-8 in neuroblastoma. To address whether Nbk loss occurred as a consequence of DNA methylation, RCC cell lines were exposed to the methylation inhibitor $5^{\prime}$-aza-2'deoxycytidine $\left(5^{\prime} a z a-2^{\prime} \mathrm{dC}\right)$. Treatment with this compound
Table 2 Differential gene expression of proapoptotic Bcl-2 family genes in Caki-2 following DNA-demethylating treatment ${ }^{\mathrm{a}}$

\begin{tabular}{lrrc}
\hline & $\begin{array}{c}\text { Signal of } \\
\text { medium control }\end{array}$ & $\begin{array}{c}\text { Signal of 5'aza- } \\
\text { 2'dC-treated cells }\end{array}$ & $\begin{array}{c}\text { Fold } \\
\text { increase }\end{array}$ \\
\hline Bax & $319.4(\mathrm{P})$ & $396.4(\mathrm{P})$ & 1.24 \\
Bak & $202.7(\mathrm{P})$ & $235.5(\mathrm{P})$ & 1.16 \\
Bok/Mtd & $3(\mathrm{~A})$ & $4.1(\mathrm{~A})$ & 1.37 \\
Nbk/Bik & $85.5(\mathrm{P})$ & $280.5(\mathrm{P})$ & 3.28 \\
Bim & $4.4(\mathrm{~A})$ & $22.2(\mathrm{~A})$ & 5.05 \\
Bid & $194.2(\mathrm{P})$ & $181.7(\mathrm{P})$ & 0.94 \\
Bad & $93.8(\mathrm{P})$ & $137.8(\mathrm{P})$ & 1.47 \\
Puma & $342.6(\mathrm{P})$ & $403.6(\mathrm{P})$ & 1.18 \\
Noxa & $92.7(\mathrm{P})$ & $104.9(\mathrm{P})$ & 1.13 \\
Hrk & $74(\mathrm{P})$ & $48.4(\mathrm{P})$ & 0.65 \\
BNIP3 & $1632.4(\mathrm{P})$ & $1671.6(\mathrm{P})$ & 1.02 \\
& & &
\end{tabular}

${ }^{a}$ Affymetrix U133A analysis in the cell line Caki-2 in the presence of the DNA methylation inhibitor $5^{\prime}$-aza-2'-deoxycytidine $\left(5^{\prime}\right.$ aza-2' $\left.\mathrm{dC}\right)$ compared to untreated cells ${ }^{b}$ Average difference of signal strength, fold change and absolute call $(A=$ absent; $P=$ present $)$ is depicted

resulted in an increased expression of Nbk mRNA and protein, but had no effect on BJAB B lymphoid, Burkitt-like lymphoma cells that ectopically expresses endogenous $\mathrm{Nbk}$ 19, and therefore served as a positive control (Figure 2).

To study whether loss of Nbk coincides with a general loss of BH3-only expression, we performed mRNA expression profiling in the Caki-2 line following induction with $5^{\prime}$ aza- $2^{\prime} \mathrm{dC}$ (Table 2). Expression of multidomain proapoptotic Bcl-2 homolog Bax and Bak mRNA was unaffected following $5^{\prime}$ aza-2'dC treatment. Expression of the ovarian-specific Bax/Bak homolog Bok was below the detection limit. Analysis of BH3-only mRNA expression confirmed that loss of $\mathrm{Nbk}$ occurs at the mRNA level, that is, through a transcriptional mechanism. Notably, we found other $\mathrm{BH} 3$-only proteins to be expressed at low, marginally detectable levels: Bim, Noxa, harakiri (Hrk) and Bad. In contrast, Puma, Bid and BNIP3 were readily detectable. Exposure to $5^{\prime} \mathrm{aza}-\mathrm{2}^{\prime} \mathrm{dC}$ resulted in strong upregulation of Nbk mRNA. Likewise, Bim expression was induced upon demethylation treatment, but remained below the cutoff for significant expression (absolute call 'absent'). To corroborate these data, Nbk mRNA was measured by quantitative real-time PCR. In fact, exposure to $5^{\prime}$ aza- $2^{\prime} \mathrm{dC}$ resulted in a $7.4 \pm 0.8$-fold induction of $\mathrm{Nbk}$ mRNA expression (Figure 3). In accordance with the DNA array data, mRNA expression levels of all other BH3-only mRNAs and the multidomain proteins Bax, Bak and Bok remained unaffected.

Notably, one of the RCC lines, RCC-MF, showed no Nbk/ Bik-expression upon $5^{\prime}$ aza-2'dC treatment (Figure 2). To further address this phenomenon and the mechanism of Nbk loss in RCC, chromosomal deletions affecting the NBK locus were analyzed by interphase FISH. Four of the cell lines including RCC-MF exhibited interphase FISH signal patterns suggesting loss of the NBK/BIK gene locus at 22q13.2. Surprisingly, Caki-2 cells showed a signal pattern suggesting gain of the NBK gene locus. Nevertheless, Caki-2 exhibits rather low constitutive Nbk protein expression that is, however, strongly increased upon demethylation. Together with the protein and RNA expression data (Figures 2 and 3), these FISH analyses indicate that chromosomal losses of the NBK/BIK gene locus contribute to the loss of Nbk expression. 
Three of the four RCC lines with NBK/BIK loss exhibited increased mRNA expression upon exposure to $5^{\prime}$ aza-2' dC, which led to increased protein expression, however, only in RCC-AB cells, whereas Nbk mRNA was induced in $6 / 6$ and Nbk protein in $5 / 6$ of the RCC cells without $N B K / B I K$ loss.

In view of Nbk being regulated by $\mathrm{p} 53$ in an E1a-sensitive manner, ${ }^{17}$ we adenovirally overexpressed p53 to check for

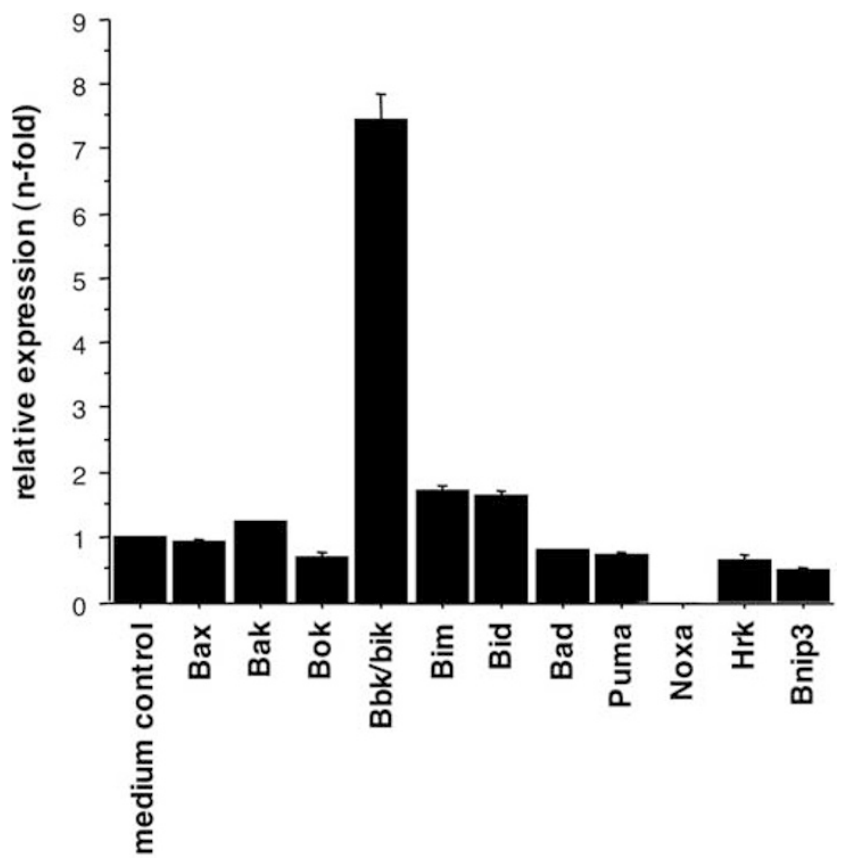

Figure 3 Analysis of $\mathrm{BH} 3$-only $\mathrm{mRNA}$ expression upon exposure to demethyling agent $5^{\prime}$-aza-2'-deoxycytidine. Quantitative real-time RT-PCR in the cell line Caki-2 shows $7.4+0.8$-fold increase of Nbk expression upon culture in the presence of the DNA methylation inhibitor $5^{\prime}$-aza-2'-deoxycytidine (5'-aza$\left.2^{\prime}-d C\right)$. Means \pm S.D. from three independent experiments are shown. Bax, Bak, Bok and mRNA expression of other $\mathrm{BH} 3$-only proteins remains largely unaffected. Noxa was undetectable by real-time PCR in Caki-2 inducibility of Nbk expression by p53 in a panel of RCC cells. Apart from Nbk, we analyzed expression of the BH3-only proteins Bim and Puma and the p53 target gene p21 CIP/WAF-1 as a control for p53 function. In five of the seven RCC lines tested, p53 signaling resulted in enhanced p21 CIP/WAF-1 expression (RCC-MF, RCC-HB, RCC-HS, RCC-GW and RCC-26). In RCC-KP, p21 ${ }^{\text {CIP/WAF-1 }}$ showed constitutive high expression and Caki-2 showed no inducible p21 expression at all, indicative of a general defect in p53 signaling as described earlier for other RCC cells. ${ }^{21}$ In RCC-MF, weak Nbk expression was induced by ectopic adenoviral p53 expression (Figure 4), corroborating that $\mathrm{Nbk}$ is a p53-inducible gene. Notably, no Nbk induction was observed in the six other RCC lines tested. Likewise, constitutive, noninducible expression of $\operatorname{Bim}_{E L}$ and Bim (but not of Bim $_{S}$ ) was found in RCC-MF, while all other lines lacked Bim expression. In contrast, Puma was readily detectable and the expression followed a similar pattern as that of p21 CIP/WAF-1 upon enforced expression of wild-type p53. Thus, loss of $\mathrm{Nbk}$ coincides with a selective failure to express Bim protein (and possibly Noxa, Hrk and Bad as well), whereas Puma protein is expressed both constitutively and in a p53-inducible manner.

To further explore the mechanism of Nbk inactivation, we screened for Nbk mutations in 57 tumor samples and in the RCC lines. Single-strand conformation polymorphism (SSCP) PCR and sequencing were informative in 52/57 tumors and revealed two aberrations. A monoallelic single-nucleotide polymorphism (SNP) leading to an amino-acid exchange at codon 26 (ACC to ATC, threonin to isoleucin) was found in three primary tumors and in the cell line RCC-LR. Furthermore, 48/52 tumors expressed an intronic CT deletion within the polypyrimidine tract upstream of the $3^{\prime}$ splice at the intron 3/exon 4 boundary as compared with the Nbk gene database entries (Figure 5). The CT deletion was homozygous in 23/52 tumors and heterozygous in 25/52 tumors. Mono- or biallelic CT deletions showed, however, no differences in the level of residual Nbk/Bik-protein expression between these RCC

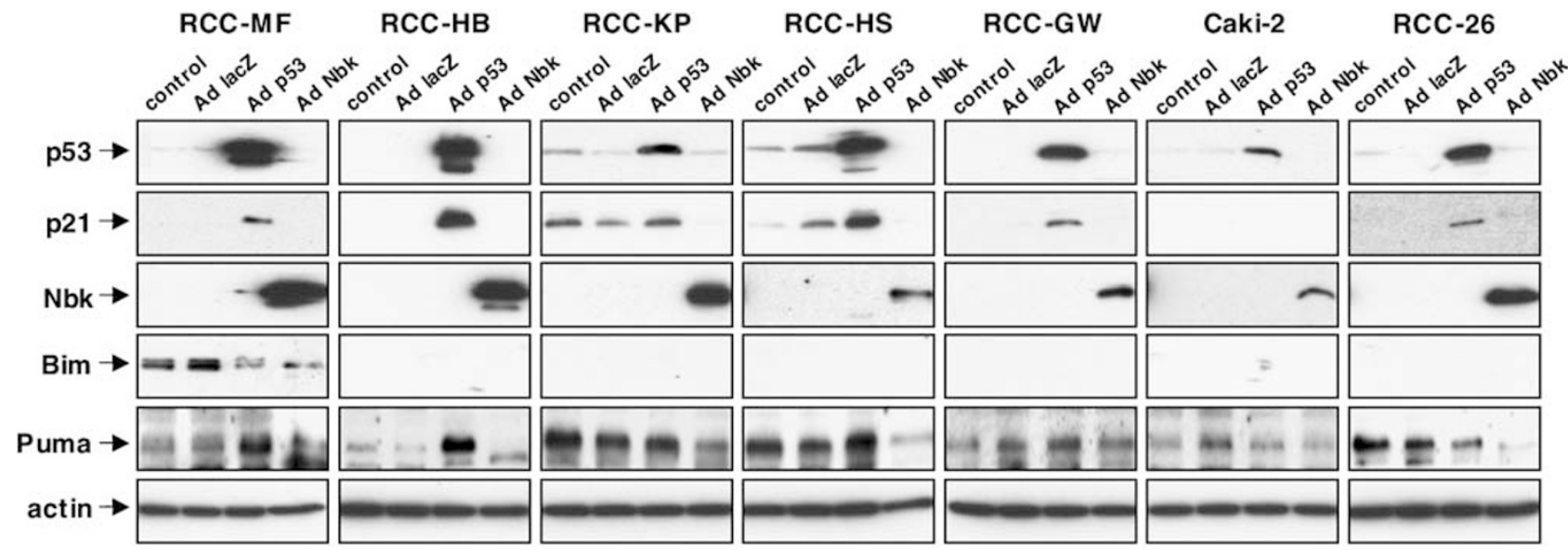

Figure 4 Analysis of p53 inducibility of BH3-only protein expression. Constitutive protein expression and inducibility of Nbk expression as compared with the BH3-only proteins Puma and Bim was determined by Western blot analysis. Cells were stressed either by adenoviral overexpression of p53 or Nbk. Ad-LacZ served as a negative control for adenoviral gene transfer. Ad-Nbk served both as a positive control for Nbk expression and as an independent cellular stress stimulus. Expression of Bim $\mathrm{FL}_{\mathrm{L}}$ and Bim (but not Bim $_{\mathrm{S}}$ ) was detected in RCC-MF but not in the other six RCC lines. Constitutive expression of Nbk was absent in all seven lines, but was inducible by p53 in RCC-MF. Puma was expressed constitutively and was inducible upon p53 overexpression. Analysis of p21 ${ }^{\text {CIPMAF-1 }}$ expression served as a control for p53 function. Detection of actin was performed as a loading control 


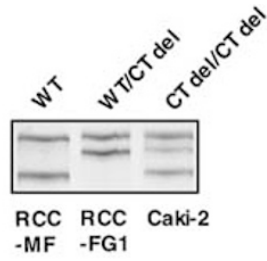

Exon 4

wild type:

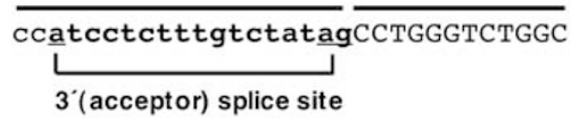

intronic

CT deletion: ccattc. .ctttgtctatagCCTGGGTCTGGC

b wild homozygous
type CT deletion

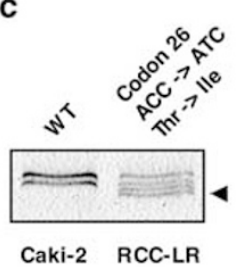

nbk (483 bp)

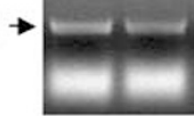

B-actin (416 bp)

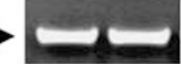

Figure 5 Detection of genetic aberrations of the NBK gene. (a) Detection of homo- and heterozygous CT deletion by SSCP-PCR and DNA sequencing in intron 3. The CT deletion occurs in the intimate vicinity of the $3^{\prime}$ splice site of the intron3/exon 4 boundary. (b) To detect alternative splicing products that might have occurred as a consequence of a splicing defect in cells carrying the CT deletion, intron 3 spanning PCR was performed. As only a single band was detected, the CT deletion does not appear to affect mRNA processing. (c) Detection of a codon 26 SNP by SSCP-PCR. DNA sequencing identified the aberrant bands detected by SSCP-PCR screening as ACC $\rightarrow$ ATC/Thr $\rightarrow \| l e$ polymorphism

tumors (Mann-Whitney $U$-test, $P=0.71$ ). To exclude that this CT deletion affects Nbk mRNA splicing, we performed RTPCR analyses spanning intron 3 of the Nbk gene. These analyses revealed, however, no alternative transcripts (Figure 5). Likewise, there was no significant difference in residual Nbk expression between the three tumors carrying the monoallelic SNP in codon 26 and the 54 wild-type tumors (Mann-Whitney $U$-test $P=0.78$ ). Therefore, both the intronic CT deletion and the codon 26 SNP most likely represent genetic polymorphisms that do not impact Nbk protein expression. This is supported by the detection of both the codon 26 SNP and the intron 3 CT deletion in nonmalignant renal tissue (data not shown).

To address the functional consequences of Nbk loss, we aimed to reconstitute Nbk expression. Efforts to stably reexpress Nbk in the RCC cell lines were not successful and we therefore established a single-vector conditional adenoviral expression system that carries $\mathrm{Nbk}$ under the control of the Tet-off expression system and has a $100 \%$ transduction

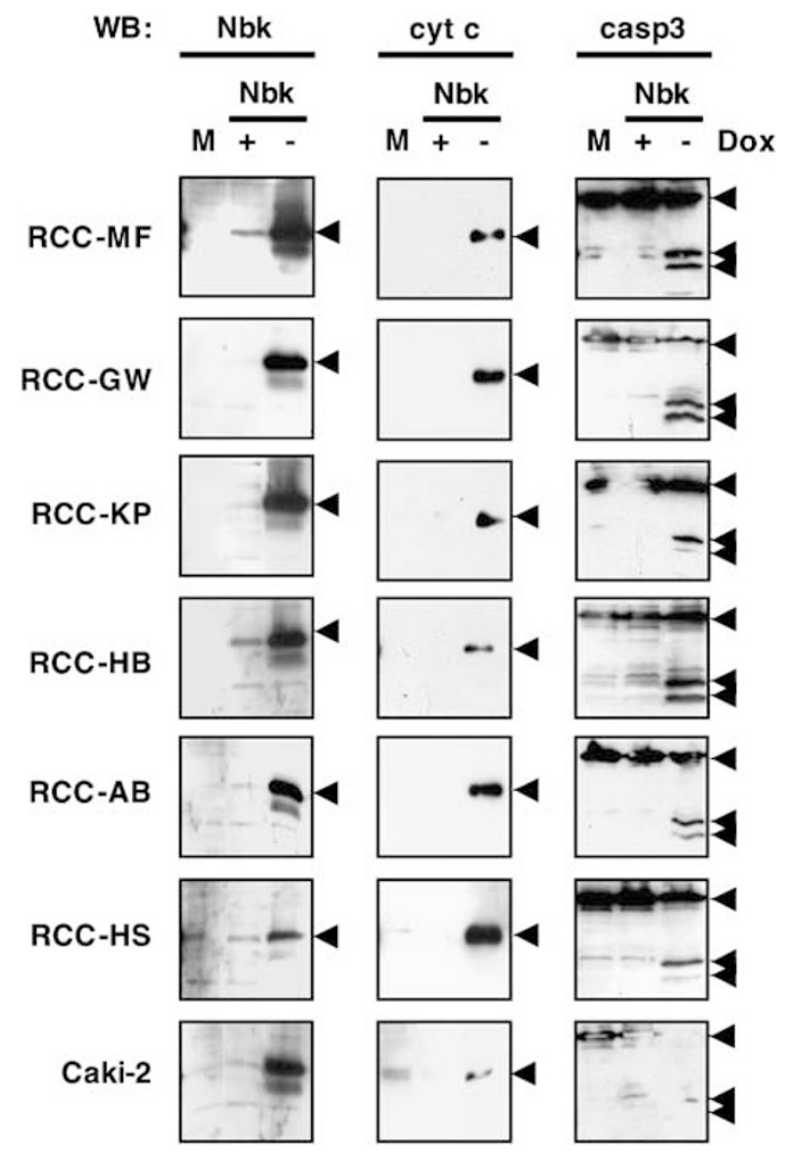

Figure 6 Nbk expression induces cytochrome $c$ release and caspase activation in RCC cells. RCC cells were incubated in the presence of medium (M) or the conditional adenoviral Nbk expression vector that contains Nbk under the control of the Tet-off system in the presence (+ Dox) or absence of doxycyclin (-Dox). In the presence of doxycyclin (+ Dox), the expression is switched off and Nbk expression is switched on in the absence of doxycyclin. Western blot analyses for Nbk expression, cytochrome $c$ release and caspase-3 activation are shown. Arrows indicate Nbk (left row), cytochrome $c$ (middle row), procaspase-3 and processing to the 16 and $18 \mathrm{kDa}$ subunits (right row)

efficacy at low multiplicities of infection. This vector provides the tetracycline-responsive transactivator in cis and is switched off in the presence of doxycyclin. ${ }^{9}$ When this vector was employed for $\mathrm{Nbk}$ expression in the absence of doxycyclin, RCC cells released cytochrome $c$ and underwent caspase-3 activation (Figure 6). This was accompanied by execution of apoptosis as determined by measurement of genomic DNA fragmentation on the single-cell level in RCC cells (Figure 7a). In contrast, nonmalignant renal epithelial cells were protected from Nbk-induced apoptosis (Figure 7b). Induction of apoptosis was associated with dissipation of the mitochondrial membrane potential in the RCC cells, but not in the nonmalignant renal cells. This indicates that reconstitution of $\mathrm{Nbk}$ initiates the mitochondrial apoptosis pathway in RCC cells. Moreover, sensitivity to apoptosis induced by Nbk seems to be restricted to malignant cells, but not nonmalignant renal epithelial cells. Thus, loss of Nbk is critical to maintain the viability of RCC cells and this indirectly suggests that Nbk may act as a tumor suppressor gene in RCC. 


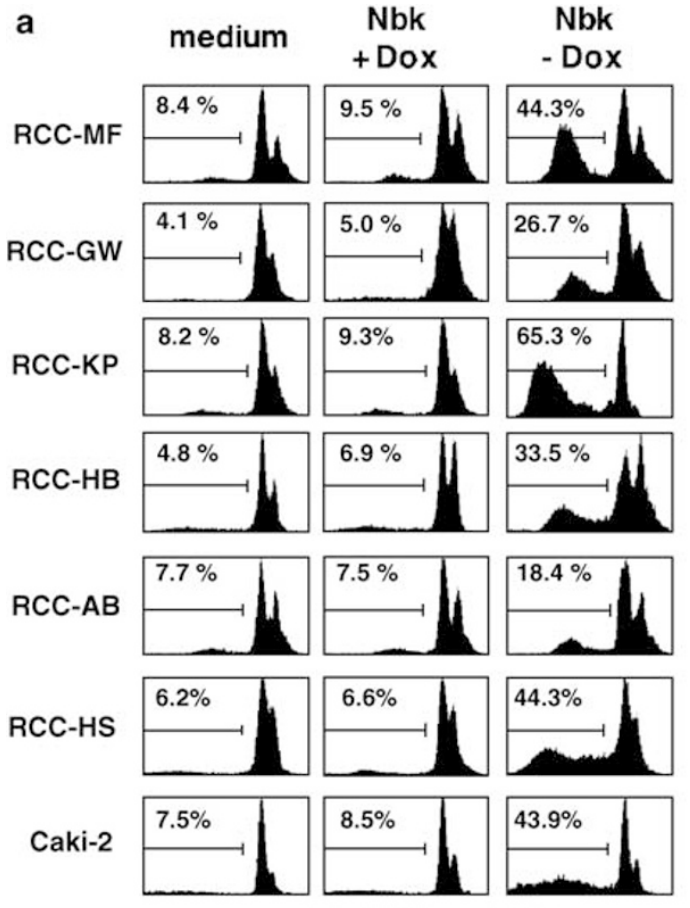

relative DNA content b
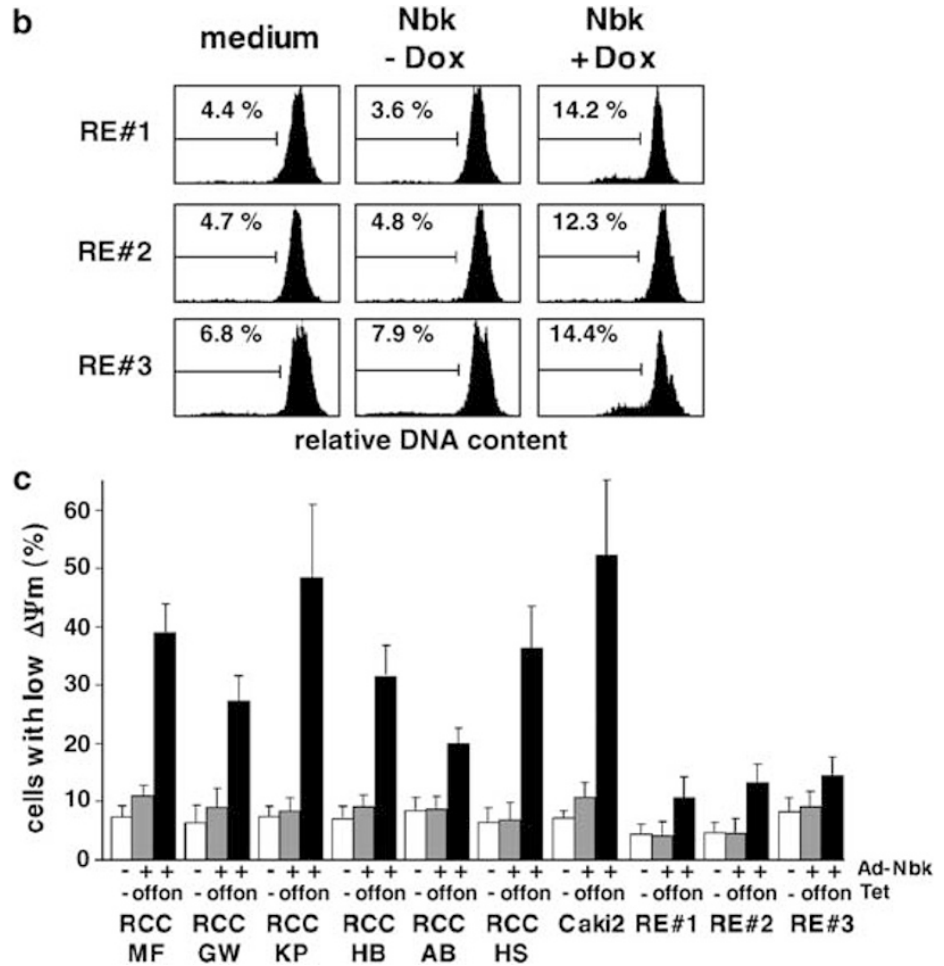

Figure 7 Reconstitution of Nbk expression induces apoptosis in RCC but not in nonmalignant renal epithelial cells. (a) RCC cells were incubated in the presence of medium (M) or the conditional adenoviral Nbk expression vector that contains Nbk under the control of the Tet-off system in the presence (+ Dox) or absence of doxycyclin (-Dox). Reconstitution of Nbk expression induced apoptosis in RCC cells (a), whereas cultures of nonmalignant, primary epithelial cells (RE\#1-RE\#3) were protected from Nbk-induced cell death (b). Apoptosis was determined by flow cytometric analysis of genomic DNA fragmentation, that is, the occurrence of a sub-G1, hypodiploid DNA content. (c) Induction of mitochondrial membrane potential breakdown by Nbk in RCC as compared with primary renal epithelial cells (RE\#1-RE\#3)

\section{Discussion}

$\mathrm{BH} 3$-only proteins are structurally distinct members of the Bcl2 family. Unlike the multidomain proapoptotic proteins Bax and $\mathrm{Bak}$, they possess only one of the $\mathrm{BH}$ signature domains, a nine-amino-acid stretch termed $\mathrm{BH} 3$ region. ${ }^{22}$ Various studies have shown that these proteins are essential initiators of programmed cell death in species as distantly related as mice and Caenorhabditis elegans. Structural and functional analyses have demonstrated that the $\mathrm{BH} 3$ domain is required for their ability to bind to $\mathrm{Bcl}$-2-like prosurvival proteins and to initiate apoptosis. ${ }^{5,23,24} \mathrm{BH}$-only proteins mediate cell death through the induction of a conformational switch in $\mathrm{Bax}^{9,25}$ or Bak. ${ }^{26,27}$ This is associated with the redistribution of Bax from the cytoplasm to membranes of cellular organelles including the mitochondria. There, Bax and Bak oligomerize and mediate the release of cytochrome $c$ and other apoptogenic factors into the cytosol. This ultimately leads to the activation of the caspase cascade and other protease systems that execute the final stages of apoptosis and the demise of the cell. ${ }^{1}$ Genetic studies in mice and human tumors established that loss of Bax and Bak renders cells refractory to BH3-only protein-induced apoptosis. ${ }^{4,8,9}$

Interestingly, BH3-only proteins link various upstream signals including the p53 pathway and oncogene-driven cell death to the intrinsic apoptosis pathway. Mutations in BH3only proteins were therefore suggested to be pathogenic in human cancer. ${ }^{22}$ So far there is, however, only scarce evidence for this hypothesis. Data from knockout mice indicate that loss of Bad or Bim may facilitate lymphomagenesis. No such data are available regarding human tumors. Here, we report for the first time that disruption of a tissuespecific $\mathrm{BH} 3-$ only protein is a general principle in a human cancer, clear-cell RCC. The tissue-specific expression pattern of Nbk with high expression found only in the kidney ${ }^{19}$ or the involuting mammary gland ${ }^{20}$ prompted us to investigate Nbk expression in RCC. There, we observed loss of Nbk expression as compared to nonmalignant renal epithelia. The failure to express Nbk is apparently due to both genomic deletion and transcriptional silencing by hypermethylation, whereas NBK gene mutation does not appear to represent a major mechanism. In RCC lines, deletion of the NBK gene at 22q13.2 was observed in four of 10 cell lines. Thus, similar to other tumor suppressor genes, transcriptional silencing may represent a key step to silence the second allele in case of LOH. Loss of Nbk was a common feature of all RCC tumors and cell lines studied, and was not related to metastatic disease, lymph node infiltration, grading or tumor size. Thus, loss of Nbk represents a unifying genetic event that might play a critical role in tumorigenesis, but less likely in tumor progression and associated secondary genetic events. Moreover, we provide evidence that loss of Nbk coincides with lack of Bim, but not of Puma protein expression. Expression profiling furthermore suggests that this lack of Nbk and Bim expression coincides with lack of Noxa, Hrk and Bad. Lack of both Bim protein and mRNA expression indicated that Bim 
might be lost through a similar mechanism as $\mathrm{Nbk}$, that is, as a consequence of gene methylation. This is, at least in Caki-2, not supported by real-time PCR analyses that failed to detect a significant increase in mRNA expression of Bim and other $\mathrm{BH} 3-o n l y$ factors or multidomain Bcl-2 homologs Bax, Bak and Bok following DNA-demethylating treatment by use of $5^{\prime}$ aza-2' dC. The reason for the failure to express some but not all $\mathrm{BH} 3-$ only proteins remains enigmatic, but nevertheless suggests that Puma and other $\mathrm{BH}$-only proteins including Bid and BNIP3 do not follow the same pattern of epigenetic regulation in malignant tumors. This has important implications for anticancer therapies that rely on Puma, ${ }^{3}$ such as ionizing irradiation or some anticancer drugs. In fact, Puma was inducible following induction by $\mathrm{p} 53$, indicating that this part of the p53 signaling axis is intact in RCC. Likewise, the use of the death ligand TRAIL alone ${ }^{28}$ or in combination with DNA-damaging anticancer therapies critically depends on the $\mathrm{BH} 3-$ only protein Bid for transduction of the cell death signal, ${ }^{29,30}$ and this part of TRAIL signaling should remain operative in RCC.

Notably, restoration of Nbk expression resulted in apoptotic death of RCC cells, whereas nonmalignant renal epithelial cells displayed a significant resistance towards $\mathrm{Nbk}$ reexpression. This supports the notion that Nbk acts as tumor suppressor. Moreover, Nbk was shown to be a transcriptional target of $\mathrm{p} 53^{17}$ and to act in the DNA damage response pathway. ${ }^{18}$ Thus, disruption of Nbk appears to represent an important event in the selection process leading to the impressive resistance to apoptosis and anticancer therapy usually observed in RCC. Nonetheless, knockout mice for Blk, a putative murine Nbk homolog, so far lack a phenotype. This may point out that like in the case of $\mathrm{Bcl}-2$ overexpression, additional genetic events are required apart from Nbk loss to facilitate oncogenesis. ${ }^{31}$ So far, the reasons for the distinct sensitivity of the malignant versus the nonmalignant renal cells remain enigmatic. An underlying mechanism could reside in the higher expression of antiapoptotic $\mathrm{Bcl}-2$ family members such as $\mathrm{Bcl}-2$ or $\mathrm{Bcl}-\mathrm{x}_{\mathrm{L}}$ that are known to interfere with Nbk-induced apoptosis. Alternatively, Nbk might be counteracted by so far undefined inhibitor in normal cells as compared with carcinoma. In addition, post-translational modification of Nbk has been described and this might affect the function of Nbk in the normal renal epithelial cells, albeit physiological stress stimuli seem to induce Nbk at the transcriptional level. ${ }^{20}$

Apart from the tissue-specific $\mathrm{BH} 3$-only protein $\mathrm{Nbk}$, expression of additional $\mathrm{BH} 3-$ only proteins is affected in RCC. Specifically, a panel of RCC lines failed to express Bim protein, whereas the p53 target Puma was inducible upon ectopic p53 expression. Thus, the impressive apoptosis resistance of $\mathrm{RCC}$ cells may arise from an additive defect to express $\mathrm{BH} 3-o n l y$ proteins that may synergize with $\mathrm{Nbk}$ as recently shown for Nbk and Noxa. ${ }^{32}$ While two of these $\mathrm{BH} 3-$ only proteins, Nbk and Noxa, act within the p53 signaling cascade, Bim is in general not recognized as a p53-inducible gene. Nevertheless, ionizing irradiation has been described to induce Bim expression through a p53-controlled mechanism. ${ }^{33}$ Thus, combined loss of $\mathrm{BH} 3$-only proteins may not only result in resistance to therapy and tumor progression, but may contribute to the general disruption of p53 signaling in $\mathrm{RCC}{ }^{21}$
Finally, our finding that $\mathrm{Nbk}$ - similar to other proapoptotic and cell cycle inhibitory genes - is lost as a consequence of epigenetic silencing offers the potential for therapeutic intervention, for example, by interfering with DNA methylation and histone acetylation. Apart from directly inducing cell death through such remodeling of the transcriptome, a practical approach might reside in the enhancement of chemosensitivity upon re-expression of Nbk by such strategies. ${ }^{18}$

\section{Materials and Methods}

\section{Clinical samples and immunohistochemistry}

Immunohistochemistry of paraffin-embedded tissue specimen was performed as described ${ }^{34}$ by the use of polyclonal goat anti-Nbk antibody (N-19 or C20; Santa Cruz, CA, USA). RCC samples from 57 patients were analyzed. In 28 patients, nonmalignant renal tissue was available. Clinicopathological characteristics are given in Table 1. Analysis of slides was carried out in a blind manner, without the knowledge of clinicopathological data. Four high-power fields $(\times 400)$ were evaluated for localization and percentage of positive cells (0-100\%). Staining intensities were graded between 0 (negative) and 3 (strong expression). Staining indices were calculated by multiplying percentages of positive cells and staining intensities as described. ${ }^{35}$

\section{Cell culture}

RCC cell lines were obtained from CLS (Heidelberg, Germany). Cells were grown in RPMl 1640 supplemented with 10\% FCS, $100 \mathrm{U} / \mathrm{ml}$ penicillin and $0.1 \mu \mathrm{g} / \mathrm{ml}$ streptomycin (GIBCO-Invitrogen, Karlsruhe, Germany). For treatment with $5^{\prime}$ aza-2 ${ }^{\prime} \mathrm{dC}$, cells were plated on day 0 and were treated with $5^{\prime}$ aza-2' dC (Sigma-Aldrich, Deisenhofen, Germany) at $1 \mu \mathrm{M}$ on days 2 and 4 and harvested on day 7. Adenoviral overexpression of $\mathrm{Nbk}^{9,36}$ or p5 $3^{37}$ was performed as described.

\section{Detection of apoptotic cell death}

Apoptosis was determined on the single-cell level by flow cytometric analysis measuring the DNA content of individual cells. In brief, cells were fixed on ice in 1\% formaldehyde followed by $70 \%$ ethanol and subsequent treatment with RNAse. Cells were stained with propidium iodide and cellular DNA content was determined as described. ${ }^{9}$ Data are given as the percentage of hypodiploid (sub-G1) cells, that is, cells displaying apoptotic DNA fragmentation. Breakdown of mitochondrial membrane potential was determined by the use of the cationic dye JC- 1 as described. $^{9}$

\section{Western blot analysis}

Immunoblotting was performed as described. ${ }^{9}$ Primary antibodies were polyclonal goat anti-Nbk antibody ( $\mathrm{N}-19)$ and anti-Puma- $\alpha$ against epitopes mapping at the $\mathrm{N}$-termini of the human proteins ( $\mathrm{N}-19)$ and were purchased from Santa Cruz Biotechnology (Santa Cruz, CA, USA). Other antibodies were as follows: monoclonal mouse anti-human cytochrome $c$ (clone 7H8.2C12; BD Biosciences Pharmingen, San Diego, CA, USA), polyclonal goat anti-human caspase-3 (R\&D Systems, Wiesbaden-Nordenstadt, Germany) and polyclonal rabbit anti-Bim (raised against a peptide corresponding to amino acids 22-40 of human and mouse Bim). Murine monoclonal antibodies against p21 ClP/WAF-1 (clone $6 \mathrm{~B} 6$, raised against a fusion protein between GST and full-length human 
Table 3 Primer sequences, annealing temperatures and PCR product sizes for Nbk mRNA and DNA analyses

\begin{tabular}{|c|c|c|c|c|}
\hline Exon & & Primer sequence for SSCP-PCR & Annealing temperature $\left({ }^{\circ} \mathrm{C}\right)$ & Product size (bp) \\
\hline \multirow{8}{*}{$\begin{array}{l}2 \\
2 \\
3 \\
3 \\
4 \\
4 \\
5 \\
5\end{array}$} & $\begin{array}{l}\text { Sense } \\
\text { Antisense }\end{array}$ & $\begin{array}{l}\text { TTA GGG GTC CAG TCA TAT GC } \\
\text { CCT GAA GTC ACT ATC AGG CA }\end{array}$ & 55 & 253 \\
\hline & Sense & CGG CAC AGC CAC ACC CGA CT & 57 & 169 \\
\hline & Antisense & TGT AGA GGC ATA GGG CAT AG & & \\
\hline & Sense & CTC CTG CAG TAA TGG CTT TGT C & 60 & 202 \\
\hline & Antisense & TCA GGG TCA GGG ATC TCA AGG C & & \\
\hline & Sense & CTG CCC CGA GCC TGA CTC C & 67 & 174 \\
\hline & Antisense & TGG TCA TGG GGG TGG GGC C & & \\
\hline & & Primer sequence for RT-PCR & Annealing temperature $\left({ }^{\circ} \mathrm{C}\right)$ & Product size (bp) \\
\hline \multirow{3}{*}{$\begin{array}{l}\text { Nbk } \\
\beta \text {-actin }\end{array}$} & $\begin{array}{l}\text { Sense } \\
\text { Antisense }\end{array}$ & $\begin{array}{l}\text { GTC TGA AGT AAG ACC CCT CT } \\
\text { ACT TGA GCA GCA GGT GCA GG }\end{array}$ & 60 & 483 \\
\hline & $\begin{array}{l}\text { Sense } \\
\text { Antisense }\end{array}$ & $\begin{array}{l}\text { ACC CCC AAG GCC AAC CGC GAG AAG ATG ACC } \\
\text { GGT GAT GAC CTG GCC GTC AGG CAG CTC GTA }\end{array}$ & 54 & 416 \\
\hline & & Primer sequence for real-time PCR & Annealing temperature $\left({ }^{\circ} \mathrm{C}\right)$ & Product size (bp) \\
\hline \multirow[t]{2}{*}{ Nbk } & $\begin{array}{l}\text { Sense } \\
\text { Antisense }\end{array}$ & $\begin{array}{l}\text { TTA AGT GTG GTG AAA CCG TCC A } \\
\text { CAC AGC CTG GGT CTG GCT T }\end{array}$ & 60 & 89 \\
\hline & 6-FAM probe & CAT CCC TGA TGT CCT CAG TCT GGT CGT & 68 & \\
\hline
\end{tabular}

p21) and p53 (clone D0-1, reactive against amino acids 1-45 of human p53) were purchased from BD-Pharmingen (Heidelberg, Germany). Secondary anti-goat and anti-mouse horseradish peroxidase-conjugated antibodies were from Promega (Mannheim, Germany) or Southern Biotechnology Associates (Birmingham, AL, USA). Bands were visualized by means of the enhanced chemiluminescence system and exposed to Hyperfilm (both Amersham-Buchler, Braunschweig, Germany).

\section{Analysis of Nbk RNA expression and DNA mutation}

RNA extraction and semiquantitative RT-PCR were performed according to standard procedures. ${ }^{38}$ For quantitative real-time PCR, $250 \mathrm{ng}$ of total RNA was reverse transcribed. PCR was performed using the ABI Prism 7000 sequence detection system (Applied Biosystems, Weiterstadt, Germany). The relative amounts of specifically amplified cDNA were calculated using $18 \mathrm{~S}$ rRNA as an internal reference. All reactions were carried out in triplicate. Primers and probes for Nbk/Bik and other Bcl-2 homologs were crosschecked via the ensembl.org home page of the EMBL-EBI and the Sanger Institute. For mutation analyses, DNA was extracted from paraffin-embedded tissue or cultured cells as described. ${ }^{10}$ Coding exons 2-5 of Nbk/Bik were amplified using intronic primers according to the NCBI nucleotide database (www.ncbi.nlm.nih.gov/), accession numbers AL022237.1, AF174421.1, AF174422.1, AF174431.1 and AF174441.1. Genomic PCR and SSCP analyses were performed as described. ${ }^{10}$ PCR products with aberrant SSCP pattern were sequenced by use of BigDye terminator cycle sequencing on an ABI Prism 310 sequencer (PE Applied Biosystems, Weiterstadt, Germany), using the primers employed for PCR amplification. For primer sequences see Table 3.

\section{Oligonucleotide array analysis}

RNA preparation, cDNA synthesis and labeling and U133A DNA oligonucleotide array (Affymetrix, Santa Clara, USA) hybridization were performed as described. ${ }^{39}$ Hybridization, washing and staining were performed according to the standard Affymetrix protocol. Data analysis was performed by use of the Microarray Suite software (Affymetrix).

\section{Fluorescence in situ hybridization}

Using bioinformatic resources (http://genome.ucsc.edu), clones RP3323M22 (centromeric), CTB-1191B2 (spanning) and RP3-526l14 (telomeric) were selected as FISH probes for the NBK/BIK locus at 22q13.2. The cosmid clone 91c (AC000091) containing the TBX1 gene at 22q11.2 served as internal control. The differently labeled flanking probes were pooled to obtain a break-apart assay for the detection of breakpoints; the differently labeled clones CTB-1191B2 and $91 \mathrm{c}$ were pooled to investigate genomic imbalances affecting the NBK/BIK locus. The triple color probe set CEPX/CEPY/CEP18 (Vysis) was applied to study ploidy. Sample preparation, denaturation, hybridisation, washings and counterstaining followed the standard protocols. ${ }^{40}$

\section{Acknowledgements}

We thank Jana Rossius and Antje Richter for expert technical assistance. This study was supported by the Deutsche Forschungsgemeinschaft and the Deutsche Krebshilfe.

\section{References}

1. Daniel PT, Schulze-Osthoff K, Belka C and Güner D (2003) Guardians of cell death: the Bcl-2 family proteins. Essays Biochem. 39: 73-88

2. Puthalakath $\mathrm{H}$ and Strasser $A$ (2002) Keeping killers on a tight leash: transcriptional and post-translational control of the pro-apoptotic activity of BH3-only proteins. Cell Death Differ. 9: 505-512

3. Villunger A, Michalak EM, Coultas L, Mullauer F, Bock G, Ausserlechner MJ, Adams JM and Strasser A (2003) p53- and drug-induced apoptotic responses mediated by $\mathrm{BH} 3-$ only proteins puma and noxa. Science 302 : 1036-1038

4. Zong WX, Lindsten $T$, Ross $A J$, MacGregor $G R$ and Thompson $C B$ (2001) BH3-only proteins that bind pro-survival Bcl-2 family members fail to induce apoptosis in the absence of Bax and Bak. Genes Dev. 15: $1481-1486$

5. Cheng EH, Wei MC, Weiler S, Flavell RA, Mak TW, Lindsten T and Korsmeyer SJ (2001) Bcl-2, Bcl-xL sequester BH3 domain-only molecules preventing Baxand Bak-mediated mitochondrial apoptosis. Mol. Cell 8: 705-711

6. Chen L, Willis SN, Wei A, Smith BJ, Fletcher JI, Hinds MG, Colman PM, Day $\mathrm{CL}$, Adams JM and Huang DC (2005) Differential targeting of prosurvival Bcl-2 
proteins by their $\mathrm{BH} 3-$ only ligands allows complementary apoptotic function. Mol. Cell 17: 393-403

7. Cartron P-F, Juin P, Oliver L, Martin S, Meflah K and Vallette FM (2003) Nonredundant role of Bax and Bak in Bid-mediated apoptosis. Mol. Cell. Biol. 23: 4701-4712

8. Yu J, Wang Z, Kinzler KW, Vogelstein B and Zhang L (2003) PUMA mediates the apoptotic response to p53 in colorectal cancer cells. Proc. Natl. Acad. Sci. USA 100: 1931-1936

9. Gillissen B, Essmann F, Graupner V, Starck L, Radetzki S, Dörken B, SchulzeOsthoff $\mathrm{K}$ and Daniel PT (2003) Induction of cell death by the BH3-only Bcl-2 homolog Nbk/Bik is mediated by an entirely Bax-dependent mitochondrial pathway. EMBO J. 22: 3580-3590

10. Sturm I, Kohne CH, Wolff G, Petrowsky H, Hillebrand T, Hauptmann S, Lorenz M, Dörken B and Daniel PT (1999) Analysis of the p53/BAX pathway in colorectal cancer: low BAX is a negative prognostic factor in patients with resected liver metastases. J. Clin. Oncol. 17: 1364-1374

11. Sturm I, Petrowsky H, Volz R, Lorenz M, Radetzki S, Hillebrand T, Wolff G, Hauptmann S, Dörken B and Daniel PT (2001) Analysis of p53/BAX/p16(ink4a/ CDKN2) in esophageal squamous cell carcinoma: high BAX and p16(ink4a/ CDKN2) identifies patients with good prognosis. J. Clin. Oncol. 19: 2272-2281

12. McCurrach ME, Connor TM, Knudson CM, Korsmeyer SJ and Lowe SW (1997) Bax-deficiency promotes drug resistance and oncogenic transformation by attenuating p53-dependent apoptosis. Proc. Natl. Acad. Sci. USA 94: 2345-2349

13. Yin C, Knudson CM, Korsmeyer SJ and Van Dyke T (1997) Bax suppresses tumorigenesis and stimulates apoptosis in vivo. Nature 385: 637-640

14. Ranger AM, Zha J, Harada H, Datta SR, Danial NN, Gilmore AP, Kutok JL, Le Beau MM, Greenberg ME and Korsmeyer SJ (2003) Bad-deficient mice develop diffuse large B cell lymphoma. Proc. Natl. Acad. Sci. USA 100: 9324-9329

15. Egle A, Harris AW, Bouillet P and Cory S (2004) Bim is a suppressor of Mycinduced mouse B cell leukemia. Proc. Natl. Acad. Sci. USA 101: 6164-6169

16. Zinkel SS, Ong CC, Ferguson DO, Iwasaki H, Akashi K, Bronson RT, Kutok JL, Alt FW and Korsmeyer SJ (2003) Proapoptotic BID is required for myeloid homeostasis and tumor suppression. Genes Dev. 17: 229-239

17. Mathai JP, Germain M, Marcellus RC and Shore GC (2002) Induction and endoplasmic reticulum location of BIK/NBK in response to apoptotic signaling by E1A and p53. Oncogene 21: 2534-2544

18. Radetzki S, Kohne $\mathrm{CH}$, von Haefen C, Gillissen B, Sturm I, Dörken B and Daniel PT (2002) The apoptosis promoting Bcl-2 homologues Bak and Nbk/Bik overcome drug resistance in Mdr-1-negative and Mdr-1-overexpressing breast cancer cell lines. Oncogene 21: 227-238

19. Daniel PT, Pun KT, Ritschel S, Sturm I, Holler J, Dörken B and Brown R (1999) Expression of the death gene Bik/Nbk promotes sensitivity to drug-induced apoptosis in corticosteroid-resistant T-cell lymphoma and prevents tumor growth in severe combined immunodeficient mice. Blood 94: 1100-1107

20. Hur J, Chesnes J, Coser KR, Lee RS, Geck P, Isselbacher KJ and Shioda T (2004) The Bik BH3-only protein is induced in estrogen-starved and antiestrogen-exposed breast cancer cells and provokes apoptosis. Proc. Natl. Acad. Sci. USA 101: 2351-2356

21. Gurova KV, Hill JE, Razorenova OV, Chumakov PM and Gudkov AV (2004) p53 pathway in renal cell carcinoma is repressed by a dominant mechanism. Cancer Res. 64: 1951-1958

22. Huang DC and Strasser A (2000) BH3-only proteins - essential initiators of apoptotic cell death. Cell 103: 839-842

23. Kelekar A and Thompson CB (1998) Bcl-2-family proteins: the role of the $\mathrm{BH} 3$ domain in apoptosis. Trends Cell Biol. 8: 324-330

24. Sattler M, Liang H, Nettesheim D, Meadows RP, Harlan JE, Eberstadt M, Yoon HS, Shuker SB, Chang BS, Minn AJ, Thompson CB and Fesik SW (1997)
Structure of Bcl-xL-Bak peptide complex: recognition between regulators of apoptosis. Science 275: 983-986

25. Desagher S, Osen-Sand A, Nichols A, Eskes R, Montessuit S, Lauper S, Maundrell K, Antonsson B and Martinou J (1999) Bid-induced conformational change of Bax is responsible for mitochondrial cytochrome $c$ release during apoptosis. J. Cell Biol. 144: 891-901

26. Korsmeyer SJ, Wei MC, Saito M, Weiler S, Oh KJ and Schlesinger PH (2000) Pro-apoptotic cascade activates BID, which oligomerizes BAK or BAX into pores that result in the release of cytochrome $c$. Cell Death Differ. 7: 1166-1173

27. Wei MC, Lindsten T, Mootha VK, Weiler S, Gross A, Ashiya M, Thompson CB and Korsmeyer SJ (2000) tBID, a membrane targeted death ligand, oligomerizes Bak to release cytochrome $c$. Gen. Dev. 14: 2060-2071

28. Rudner J, Jendrossek V, Lauber K, Daniel PT, Wesselborg S and Belka C (2005) Type I and type II reactions in TRAIL-induced apoptosis - results from dose response studies. Oncogene 24: 130-140

29. Wendt J, Radetzki S, von Haefen C, Hemmati PG, Güner D, Schulze-Osthoff K, Dörken B and Daniel PT (2005) Induction of p21CIP/WAF-1 and G2 arrest by ionising irradiation impedes caspase-3-mediated apoptosis in human carcinoma cells. Oncogene (in press)

30. von Haefen C, Gillissen B, Hemmati PG, Wendt J, Güner D, Mrozek A, Belka C, Dörken B and Daniel PT (2004) The multidomain Bcl-2 homolog Bax but not Bak mediates synergistic induction of apoptosis by TRAIL and 5-FU through the mitochondrial apoptosis pathway. Oncogene 23: 8320-8332

31. Coultas L, Bouillet P, Stanley EG, Brodnicki TC, Adams JM and Strasser A (2004) Proapoptotic BH3-only Bcl-2 family member Bik/Blk/Nbk is expressed in hemopoietic and endothelial cells but is redundant for their programmed death. Mol. Cell. Biol. 24: 1570-1581

32. Germain M, Mathai JP, McBride HM and Shore GC (2005) Endoplasmic reticulum BIK initiates DRP1-regulated remodelling of mitochondrial cristae during apoptosis. EMBO J. 24: 1546-1556

33. Burns TF and El-Deiry WS (2003) Microarray analysis of p53 target gene expression patterns in the spleen and thymus in response to ionizing radiation. Cancer Biol. Ther. 2: 431-443

34. Sturm I, Kohne CH, Wolff G, Petrowsky H, Hillebrand T, Hauptmann S, Lorenz M, Dörken B and Daniel PT (1999) Analysis of the p53/BAX pathway in colorectal cancer: low BAX is a negative prognostic factor in patients with resected liver metastases. J. Clin. Oncol. 17: 1364-1374

35. Rau B, Sturm I, Lage H, Berger S, Schneider U, Hauptmann S, Wust P, Riess H, Schlag PM, Dörken B and Daniel PT (2003) Dynamic expression profile of p21WAF1/CIP1 and Ki-67 predicts survival in rectal carcinoma treated by preoperative radiochemotherapy. J. Clin. Oncol. 21: 3391-3401

36. Oppermann M, Geilen CC, Fecker LF, Gillissen B, Daniel PT and Eberle J (2005) Caspase-independent induction of apoptosis in human melanoma cells by the proapoptotic Bcl-2-related protein Nbk/Bik. Oncogene 24: 7369-7380

37. Brand K, Klocke R, Possling A, Paul D and Strauss M (1999) Induction of apoptosis and G2/M arrest by infection with replication-deficient adenovirus at high multiplicity of infection. Gene Therapy 6: 1054-1063

38. Radetzki S, Köhne $\mathrm{CH}$, von Haefen C, Gillissen B, Sturm I, Dörken B and Daniel PT (2002) The apoptosis promoting Bcl-2 homologues Bak and Nbk/Bik overcome drug resistance in Mdr-1-negative and Mdr-1 overexpressing breast cancer cell lines. Oncogene 21: 227-238

39. Schories B, Janz M, Dörken B and Bommert K (2004) Downregulation of genes involved in DNA repair and differential expression of transcription regulators and phosphatases precede IgM-induced apoptosis in the Burkitt's lymphoma cell line BL60-2. Biochim. Biophys. Acta 1676: 83-95

40. Martin-Subero JI, Chudoba I, Harder L, Gesk S, Grote W, Novo FJ, Calasanz MJ and Siebert R (2002) Multicolor-FICTION: expanding the possibilities of combined morphologic, immunophenotypic, and genetic single cell analyses. Am. J. Pathol. 161: 413-420 